OPEN ACCESS

Edited by: Krasimir Kolev,

Semme/weis University, Hungary

Reviewed by:

Craig N. Jenne,

University of Calgary, Canada

Robert H. Lee,

University of North Carolina at Chape

Hill, United States

*Correspondence:

Nonantzin Beristain-Covarrubias n.beristan-covarrubias@bham.ac.uk Adam F. Cunningham a.f.cunningham@bham.ac.uk

Specialty section: This article was submitted to Inflammation,

a section of the journal

Frontiers in Immunology

Received: 20 May 2019 Accepted: 16 October 2019 Published: 05 November 2019

Citation:

Beristain-Covarrubias N Perez-Toledo M, Thomas MR Henderson IR, Watson SP and Cunningham AF (2019) Understanding Infection-Induced Thrombosis:

Lessons Learned From Animal

Models. Front. Immunol. 10:2569.

doi: 10.3389/fimmu.2019.02569

\section{Understanding Infection-Induced Thrombosis: Lessons Learned From Animal Models}

\author{
Nonantzin Beristain-Covarrubias ${ }^{1 *}$, Marisol Perez-Toledo ${ }^{2}$, Mark R. Thomas ${ }^{1}$, \\ lan R. Henderson ${ }^{3}$, Steve P. Watson ${ }^{1,4}$ and Adam F. Cunningham ${ }^{2 *}$ \\ ${ }^{1}$ Institute of Cardiovascular Sciences, College of Medical and Dental Sciences, University of Birmingham, Birmingham, \\ United Kingdom, ${ }^{2}$ Institute of Immunology and Immunotherapy, College of Medical and Dental Sciences, University of \\ Birmingham, Birmingham, United Kingdom, ${ }^{3}$ Institute for Molecular Bioscience, University of Queensland, Brisbane, QLD, \\ Australia, ${ }^{4}$ Centre of Membrane Proteins and Receptors, Universities of Birmingham and Nottingham, Midlands, \\ United Kingdom
}

Thrombosis is a common consequence of infection that is associated with poor patient outcome. Nevertheless, the mechanisms by which infection-associated thrombosis is induced, maintained and resolved are poorly understood, as is the contribution thrombosis makes to host control of infection and pathogen spread. The key difference between infection-associated thrombosis and thrombosis in other circumstances is a stronger inflammation-mediated component caused by the presence of the pathogen and its products. This inflammation triggers the activation of platelets, which may accompany damage to the endothelium, resulting in fibrin deposition and thrombus formation. This process is often referred to as thrombo-inflammation. Strikingly, despite its clinical importance and despite thrombi being induced to many different pathogens, it is still unclear whether the mechanisms underlying this process are conserved and how we can best understand this process. This review summarizes thrombosis in a variety of models, including single antigen models such as LPS, and infection models using viruses and bacteria. We provide a specific focus on Salmonella Typhimurium infection as a useful model to address all stages of thrombosis during infection. We highlight how this model has helped us identify how thrombosis can appear in different organs at different times and thrombi be detected for weeks after infection in one site, yet largely be resolved within $24 \mathrm{~h}$ in another. Furthermore, we discuss the observation that thrombi induced to Salmonella Typhimurium are largely devoid of bacteria. Finally, we discuss the value of different therapeutic approaches to target thrombosis, the potential importance of timing in their administration and the necessity to maintain normal hemostasis after treatment. Improvements in our understanding of these processes can be used to better target infection-mediated mechanisms of thrombosis.

Keywords: thrombo-inflammation, pathogens, bacteria, virus, thrombosis, platelets, Salmonella 


\section{INTRODUCTION}

\section{Thrombosis Is a Deadly Complication of Infection in Humans}

Systemic or localized infections increase the risk of thrombosis $\sim 2-20$ times and are independent risk factors for thromboembolic diseases such as deep vein thrombosis (DVT)/pulmonary embolism (PE) as well as cardiovascular (myocardial infarction) and cerebrovascular events (stroke) $(1,2)$. The greatest window of risk is when the infection is active, or the weeks shortly afterwards, and in most cases the causative pathogen is not identified (2-5). All types of infection can elevate risk, although some appear to increase risk more than others. Thus, augmented risk of venous thromboembolism is observed in cases of pneumonia $(\mathrm{OR}, 3.6)$, symptomatic urinary tract (OR, 2.2 ), oral (periodontitis and gingivitis-OR, 12), intra-abdominal (OR, 18), and systemic/bloodstream infections (with or without laboratory-confirmed culture-OR, 11-21) $(1-3,6)$.

There is some discussion about the inter-relationship between infection-induced thrombosis and pre-existing risk factors, such as smoking, lipid levels, and sedentarism, in terms of whether these risk factors directly influence pathogen-driven thrombosis (5). Nevertheless, it is likely that infection promotes the risk of thrombosis in such individuals, although it is important to consider that infection alone is sufficient to drive thrombotic events (7-12). For example, ischemic stroke is associated with acute infections (particularly in the first 3 days after respiratory or urinary tract infection) as are chronic infections such as chronic bronchitis (5). Many common pathogens cause infections that can enhance the risk of thrombotic complications such as stroke. These include-Helicobacter pylori, Chlamydia pneumoniae, Mycoplasma pneumoniae, Haemophilus influenzae, Strepptococcus pneumoniae, Staphylococcus aureus, Escherichia coli, Epstein-Bar virus, herpesvirus, and cytomegalovirus (2, 5, 13). Moreover, exacerbations of cardiovascular disease, including acute myocardial infarction and unstable angina, have been observed in bacteraemic infections caused by Neisseria meningitidis and Staphylococcus aureus (14-16). This association is not limited to adults but is also observed in children in acute conditions such as sepsis, necrotizing enterocolitis, and otitis media; or in chronic pulmonary infections caused by respiratory syncytial virus or Pseudomonas aeruginosa (17). Since thrombosis is observed after infection with a diverse range of pathogens, it suggests the ultimate risk of thrombosis after infection is influenced by both host and pathogen-derived factors (15).

The pathological consequences of thrombosis during infection have been extensively studied (18-20). The key factor that underpins the risk of thrombosis is the level of inflammation that is induced by the infection, which drives a procoagulant state, with more severe infections promoting greater inflammation and higher risks of thrombotic complications. Sepsis, as the ultimate expression of an un-controlled infection, often occurs without an infective agent being identified. In sepsis there is an excessive systemic inflammatory response syndrome (SIRS), which can lead to multi-organ failure and the death of the patient (21). Sepsis is frequently associated with disseminated intravascular coagulation (DIC), a critical presentation of altered blood coagulation and microthrombus formation in the microvascular bed of different organs $(6,22,23)$. The risk of thrombotic complications after infection is not limited to the hospital setting. There is clear evidence that in the community setting, infections increase the risk of venous thromboembolic complications (DVT/PE) (1), with the host and the pathogen both determining the outcome of this relationship (16). In SIRS and DIC, inflammation is mediated by multiple cytokines such as interleukins 1,6 , and 8 (IL-1,-6, and-8), interferons (IFNs) and tumor necrosis factor $\alpha(\mathrm{TNF} \alpha)$ (24). Moreover, there is a strong association with damage-associated molecular pattern (DAMPs) molecules like DNA and histones, both as free molecules and within neutrophil extracellular traps (NETs), which are released by activated leucocytes and also promote thrombi formation (25). These combine to promote the pro-coagulant state leading to endothelial damage, platelet activation and aggregation, increases in pro-coagulant proteins such as tissue factor (TF), and reduced activity of anticoagulant mechanisms like fibrinolysis. Compounding this, pathogens themselves are often capable of modulating inflammation and the coagulation system through the production of either pro- or anti-coagulant proteins (26-28). This will be discussed in more detail later in this review.

\section{MODELS TO STUDY THROMBOSIS INDUCED BY INFECTION}

The link between infection and thrombosis has mostly been studied in the context of sepsis. Animal models that study infection-associated coagulopathy typically examine the link between high antigen burdens and the resulting hyperinflammation, often ignoring other infectious disease-mediated effects on coagulation system. One of the accompanying advances that has helped in interpreting the events revealed by these models, has been the improvements in imaging thrombosis and infection. In particular, the advent of more advanced microscopy techniques, such as intravital microscopy, has contributed to a better understanding of how the events associated with infection-induced thrombosis occur in real-time. Through these techniques, pathogen-host cell interactions can be tracked in vivo in multiple tissues (29-31). These transformative approaches have underpinned a new understanding on how multiple celltypes, such as neutrophils and platelets, interact to generate thrombi, and on occasion, bind to pathogens. Below, we summarize and discuss different models of infection and thrombosis (Figure 1), with a particular focus on the potential of these models to study not only the triggering of thrombosis but also its development and resolution.

\section{Single Microbial Component-Induced Sepsis Models}

Animal models of sepsis induced using a single product derived from pathogens are typically based on the recognition of pathogen-associated molecular patterns (PAMPs) by immune cells during infection. These models attempt to resemble 


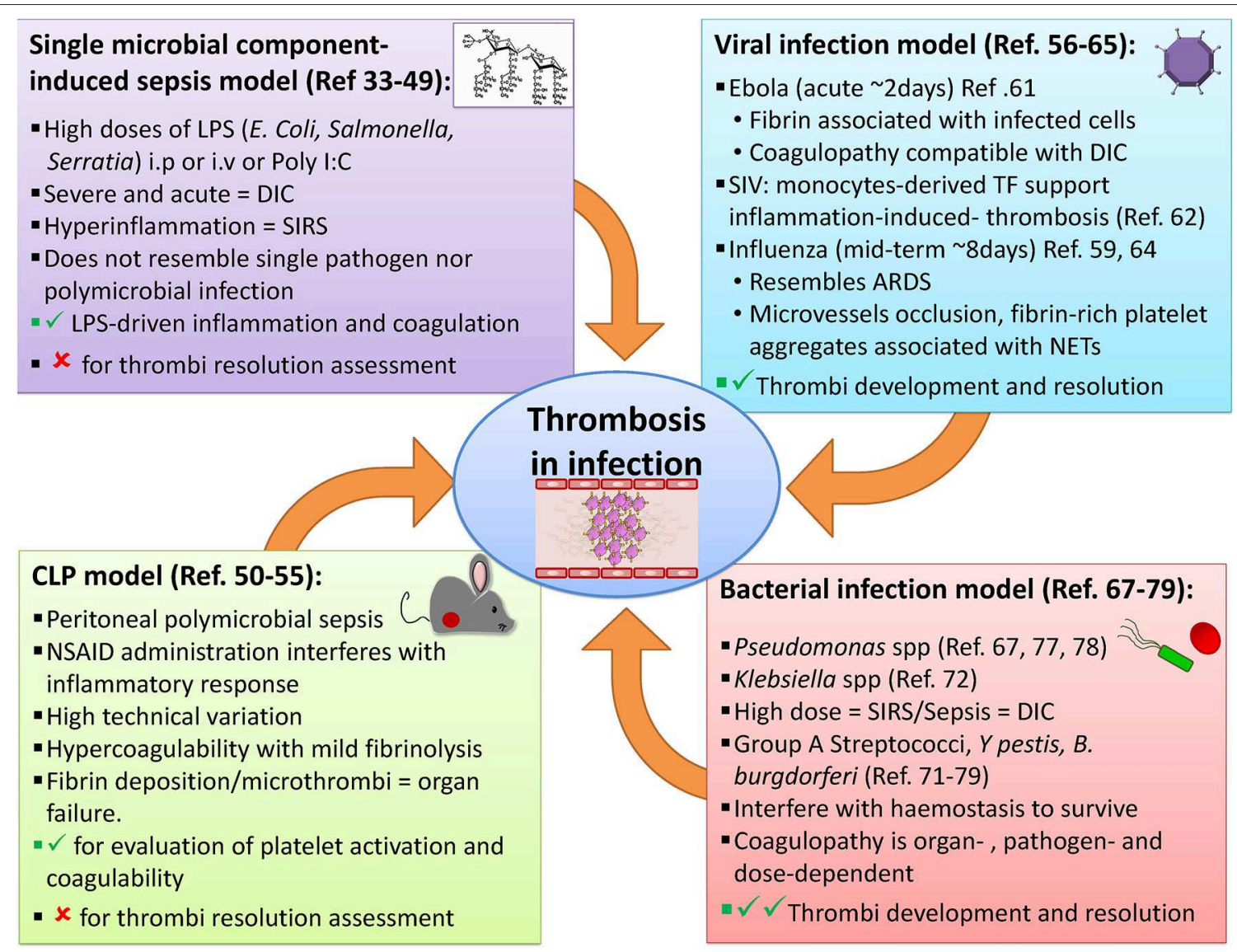

FIGURE 1 | Examples of animal models available to study thrombosis during infection. A range of approaches has been employed to evaluate infection-induced thrombosis. Single microbial component-induced sepsis, or CLP models, mimic severe sepsis in humans, but most are usually only useable for a few days either because the infection is cleared or it is lethal. Some viral and bacterial infection models can induce longer-lasting infections and thrombotic complications may also be useful to study the resolution of thrombosis.

the human septic state by injecting a single pathogenderived molecule, either intraperitoneally (i.p.) or intravenously (i.v.). The endotoxemia model induces systemic inflammation through administration of lipopolysaccharide (LPS), purified from different gram-negative bacteria (e.g., E. coli, Salmonella, or Serratia), given in doses much higher $(1-10 \mathrm{mg} / \mathrm{kg})$ than the amount potentially found in bacteria during a more realistic septic state (32). LPS is a major component of the outer cell wall of gram-negative bacteria and is recognized by host cells through multiple pathways including toll-like receptor 4 (TLR-4) (33). The fact that LPS is not a true toxin, but a cell wall component involved in maintaining structural stability, highlights how the host-derived responses to bacterial components, rather than their intrinsic toxicity, is important in driving the pro-thrombotic state. Binding of LPS by host cells such as monocytes/macrophages, platelets and endothelial cells results in a pro-coagulant state through directly activating pro-inflammatory responses concurrently with coagulation factors like monocyte-derived tissue factor (mTF) within the vasculature (34). Among the inflammatory mediators released in this sepsis model are IL-1, IL-6, TNF $\alpha$, and IFN $\gamma$ which can induce or potentiate leukocytes and endothelial cells to upregulate pro-coagulant molecules such as
TF, FVII/FVIIa, and thrombin driving thrombi generation (35). Moreover, these pro-inflammatory molecules also reduce the levels of endogenous anti-coagulant proteins, like tissue factor pathway inhibitor (TFPI), antithrombin (AT), and activated protein C (APC) (36). Together this increases the thrombotic risk of consumption pathology like DIC (37).

The LPS model has demonstrated the association between inflammation, platelet activation, and coagulation (38) and the potential of targeting the inflammatory cascade to reduce DIC severity and mortality $(34,36)$. However, few studies have examined if the resultant thrombi are efficient traps for LPS. A comparative study done with human and mouse blood as well as arthropods hemolymph, showed that the blood clot binds LPS in vitro, during or shortly after clotting (39). This study also demonstrated binding of LPS to platelets and fibrin within the clot in vivo, using a mouse model of laser-induced thrombosis in the cremaster muscle and an infusion of labeled-LPS (39). Thus, thrombi in some circumstances seem to be able to trap LPS and this has helped evolve the concept that thrombi can also trap bacteria (40).

Modest doses of alpha toxin ( $1 \mu \mathrm{g} /$ mouse i.v.) have been used to model staphylococcal sepsis $(41,42)$. Furthermore, in a later phase ( $4-8 \mathrm{~h}$ after infection), alpha toxin secreted 
during S. aureus bacteremia, is directly responsible for platelet aggregation in the microvessels. These thrombotic events in the microvasculature lead to organ dysfunction in liver and kidney correlating with disease severity. The approach used in this study (43), although acute, allows investigation of the early events during septic coagulopathy and the direct effect of pathogen products on hemostasis, and reveals the possibility of targeting the alpha toxin rather than a cell receptor therapeutically.

Polyinosinic:polycytidylic acid (Poly I:C) is a synthetic double-stranded RNA that interacts with TLR-3 and is used experimentally to mimic aspects of viral infections $(44,45)$. TLR3 expression on platelets and megakaryocytes has been reported and its ligation on platelets can potentiate platelet aggregation by other classical platelet agonists (46). The use of Poly I:C for studying thrombosis is not as widespread as for other models, but injection with Poly I:C has been described to induce TLR-3dependent arterial thrombosis, but a more minimal thrombosis in the venules (47). As there is limited data for the use of Poly $\mathrm{I}: \mathrm{C}$ in this context, more work is needed to better understand the strengths and limitations of its use to recapitulate what is observed after viral infection.

One limitation in these single-agent models is that they typically induce a highly acute systemic organ failure through the inflammation-induced deposition of fibrin in multiple organs (48). The use of single components also underplays the complexity of pathogens, which typically can induce multiple innate and adaptive pathways concurrently. It also does not take into consideration other potentially pro-thrombotic antigens that may be present in the pathogen, nor the active role that live bacteria themselves may play during sepsis (28). Moreover, during sepsis, concurrent with fibrin deposition, other systemic events are ongoing, including lowering of the blood pressure, increases in the heart and respiratory rate, arterial hypoxemia, as well as derangement of white blood cell and platelets counts. In combination, these can lead to organ dysfunction and in the most severe cases progress to septic shock and death (49). Moreover, despite its usefulness, the pathways identified using the LPS model have not translated into clinical benefit to date. Thus, single microbial component-induced sepsis models have intrinsic limitations for studying specific complications of infection such as thrombosis development or its resolution.

\section{The Cecal Ligation and Puncture Model}

The cecal ligation and puncture (CLP) model evaluates polymicrobial sepsis through the introduction of fecal contaminants into the peritoneal cavity after perforation of the cecum (32). This model resembles the peritonitis observed during a number of conditions such as appendicitis, diverticulitis, bowel perforation, and trauma. After puncture, a complex bacterial community translocates from the gut into the host. Included within this population are well-studied organisms such as different E. coli strains and other Gram-negative bacteria. In addition, there are many other bacterial genera and species present, many of which are difficult to culture. This means that although the model recreates what is observed in some clinical conditions, it can be difficult to fully appreciate the diversity of bacterial species and the total numbers of bacteria present. Furthermore, the composition of the gut microbiome should be taken into consideration when using this model as it may influence outcome. For instance, it has been reported that C57BL/6 mice from two different suppliers show differences in their survival following CLP. The immunophenotype and the level of inflammation in these animals differed after CLP. The supplier-associated effects were no longer detectable if the animals were co-housed. Thus, the microbiome can influence survival in this model (50).

After CLP, animals develop hypercoagulability with mild fibrinolysis. Only a few reports have studied thrombi formation in this model and these typically show fibrin deposition or microthrombi formation in organs such as kidney and liver $(51,52)$, highlighting the impact of coagulopathy during severe infections. Indeed, the development of thrombi rich in platelets in the microvasculature of kidney, lung, and liver has been observed $48 \mathrm{~h}$ after CLP, correlating with organ dysfunction due to ischemic complications such as kidney failure and respiratory distress syndrome (53). Moreover, sepsis-induced thrombocytopenia is attributed to the sequestration of platelets either within thrombi or complexed with leukocytes (54). Thus, the CLP model has been used to evaluate platelet activation and coagulability during peritoneal sepsis. In the CLP model, mice typically do not recover and combined with its relative acute nature (a few days) and the variability of the bacterial burden resulting from puncture, this means that it has limited value to study thrombus resolution despite its clinical relevance $(52,55)$.

\section{Viral Infection Models}

Many viral infections target hemostasis and coagulation, introducing either hemorrhagic or thrombotic complications (56). Indeed, in humans, seasonal flu vaccination can moderate the risk of some cardiovascular events (57). Among the viruses associated with thrombotic complications in humans are exanthematous viruses such as varicella, variola, measles, and vaccinia; arboviruses like dengue virus; ebola virus; and also influenza virus, hepatitis, HIV, and cytomegalovirus (58). A potential limitation here is that many viruses demonstrate exquisite host specificity meaning that equivalent viruses are not always available for study in animals.

There is strong evidence showing abnormal hemostasis linked to inflammation during viral infections in humans $(8,9,59$, $60)$. In animals, some viral infections like Ebola and influenza have been used to study thrombosis. Macaques inoculated intramuscularly with 1,000 plaque forming units (pfu) of Ebola virions, not unsurprisingly develop coagulation abnormalities compatible with DIC from day 2 after infection (61). In this study, Ebola virus (EBOV) infection induced the expression of TF in mononuclear phagocytes, triggering activation of the coagulation system (61). Moreover, this work showed histological evidence of fibrin deposits in tissues (spleen, liver, and kidney) from EBOV-infected macaques. The fibrin deposits were in association with activated macrophages and in close contact with infected cells and viral proteins, thus highlighting the interplay between inflammatory cells and coagulopathy. Monocyte-derived TF contributing to inflammation-induced thrombosis was also 
demonstrated in a Simian virus immunodeficiency model linking HIV infection with cardiovascular complications (62).

In a model of acute respiratory distress syndrome (ARDS), mice infected intranasally with a lethal dose of influenza virus were shown to have increased platelet aggregation, pulmonary microvascular thrombosis, endothelial damage and hyperinflammatory cytokine responses (59, 63, 64). Furthermore, occlusion of microvessels with fibrin-rich platelet aggregates and the presence of extracellular histones within those aggregates was shown, reflecting what has been described in endotoxemic and CLP models of sepsis $(25,65)$. This model linked the prothrombotic effects of inflammation through NETs and potentially through the secretion of platelet-derived soluble CD40 ligand (sCD40L), which can induce platelet aggregation (66). Interestingly, over $95 \%$ of sCD40L in circulation comes from platelets, which might contribute to thrombosis during infection due to its capacity to promote histone-platelet interaction (65). Mice lethally infected with influenza virus survive no more than 8 days post infection (d.p.i.) and thrombosis was observed from day 3 p.i. (65); making this model more suitable for the study of thrombi development under highly inflammatory conditions and its potential implications in the physiopathology of complications such as ARDS. Thus, viral infection models such as influenza can be used to have a better understanding of the mechanisms of thrombosis promoted by these pathogens.

\section{Bacterial Infection Models}

Multiple models use live bacteria to induce SIRS and the associated thrombo-inflammatory consequences, mimicking what happens during conditions such as sepsis (32). However, few animal models involve bacterial infections to evaluate how a long-term established infection, and the associated inflammation, may impact on the coagulation state of the host. Most in vivo models inoculate intravenously with relatively high doses of bacteria (from $1 \times 10^{7}$ to $2 \times 10^{9} \mathrm{CFU}$ (Colony Forming Units/mL, depending on the model) (67-69), which can lead to a massive induction of complement-dependent bacteria lysis and antigen release. Live and killed bacteria can activate a wide range of innate receptors known as pattern recognition receptors (PRR), such as Toll-like receptors (TLR), NOD-like receptors (NLR), and others (33). These models have informed on how pathogens can actively modulate not only the immune response, in order to escape control, but also the coagulation cascade to favor bacterial invasion (70). Examples of pathogens used in such studies include $S$. aureus, Pseudomonas aeruginosa, group A Streptococcus, Klebsiella pneumoniae, Yersinia spp, Bacillus anthracis, B. cereus, and Salmonella Typhimurium, among others $(67,68,71-75)$.

The speed of the host response is striking. Within the first $30 \mathrm{~min}$ of infection with an outbreak strain of $S$. aureus or another Gram-positive organism, Bacillus cereus, platelet aggregates are bound to Kupffer cells in the liver $(43,75)$. These aggregates can help enhance bacterial capture and limit bacterial dissemination, demonstrating the potential value of platelet interactions with host cells in host defense. Several studies using a $P$. aeruginosa-induced model of ARDS have evaluated the pro-coagulant imbalance during acute lung injury that has been associated with decreased fibrinolytic activity (67). These models highlight the capacity of early fibrin formation to limit damage, but its potential to harm if it persists (76). This led to the proposal that modulation of hemostasis, either by administration of recombinant human antithrombin (rhAT) or recombinant human activated protein $\mathrm{C}$ (rhAPC), may restore the fibrinolytic activity, then limiting the amount of inflammation $(67,76)$. Administration of rhAPC treatment or fibrin-derived peptides (B $\beta$ 15-42) can exert a protective effect during acute lung injury (ALI), without modifying the inflammatory response to $P$. aeruginosa nor the bacterial clearance $(77,78)$. Moreover, in a different model of pneumonia induced by K. pneumoniae, overexpression of human tissue-type plasminogen activator ( $t$ PA) was associated with a higher level of fibrinolysis in the lungs and decreased thrombus formation in the liver and subsequent improvements in survival of the host (68). These studies show the importance of fibrinolysis during infection and the roles coagulation/fibrinolytic factors can play in severe infections depending on the location of the infection and the pathogen.

Multiple human pathogens express coagulation-related proteins, such as Streptokinase (SK) produced by group A streptococci (GAS) and Staphylokinase from Staphylococcus aureus (71), which activate plasminogen resulting in increased fibrinolysis. These proteins are similar to the Pla protein expressed by $Y$. pestis (26), which can activate plasminogen as well as mediate bacterial adhesion to extracellular matrices aiding spread throughout host tissues (28). Other microorganisms, such as Borrelia burgdorferi, use the host plasminogen receptor to enhance migration though tissues $(27,28)$. Thus, different animal models can help understand how pathogens interact with the coagulation system and how this impacts on the pathogenicity during infection. GAS are human pathogens that cause a variety of infections, from mild pharyngeal and skin infections to necrotizing fasciitis and toxic shock-like syndrome $(71,79)$. GAS are human-specific pathogens, with limited animal models available to use for their study, although humanized transgenic mice have been used successfully to study host-pathogen interactions in vivo (71). These organisms can interfere with hemostasis to promote their survival and dissemination, partly through sequestering host plasminogen. This is then converted into plasmin, which results in degradation of the fibrin network that helps contain the bacteria, enabling escape from the clot and dissemination to other sites within the host $(71,79-82)$. Fibrin can have an important role in limiting pathogen invasion at sites of injury. This was demonstrated, using in vivo microscopy, in a wound infection model using $P$. aeruginosa in mice. This showed that fibrin mesh acts as a physical barrier to prevent bacteria from penetrating the wound, while a full clot forms a permanent seal (83). Thus, the fibrin wall induced rapidly after trauma enhances resistance to infection.

As mentioned previously, most animal models of sepsis use Gram-negative bacteria or their endotoxins to evaluate coagulopathy. A limitation of these models is that they provoke an acute endotoxemia, rather than a sustained infection. Notwithstanding this temporal constraint, these models have been used to evaluate the potential for thrombosis to aid 
host defense. After systemic infection of neutrophil serine protease-deficient mice with relatively high doses of $E$. coli $\left(3.2 \times 10^{8} \mathrm{CFU}\right)$, fibrin deposition and restriction of bacteria within the sinusoid vasculature is reduced and there is an increase in bacteria within tissues (31). Since neutrophil proteases are essential to induce NETs, the authors concluded that the reduction in fibrin deposition (microthrombi) is directly responsible for bacterial spreading into the liver. Whilst indicative of a role of NETs in restricting bacterial dissemination, other roles for serine proteases may also contribute to these effects.

Studies have also examined responses using far lower doses of bacteria in acute or chronic infection models $(72,73,84)$. An example of this is a mouse model of Bacillus anthracis infection $\left(5 \times 10^{6}\right.$ spores per mouse), which was used to study thrombus formation and composition in the liver in anthrax. The authors described thrombi in the liver microvasculature and this was associated with lethality. Most thrombi were composed of platelets, leucocytes, von Willebrand factor (VWF), Syndecan1 and fibronectin (73). They attribute the bacteria-induced endothelial injury to the clot formation. Moreover, the presence of bacteria aggregated with platelets and leukocytes supports the previously described role of inflammation in infectious coagulopathy and bacterial trapping (85). Proteins such as VWF, collagen and fibronectin contribute to the hemostatic response and to endothelial damage. Furthermore, a potentially protective role for different pro-coagulant mediators such as fibrin, TF, plasminogen activator inhibitor-1 (PAI-1) and TAFI have been described during $Y$. enterocolitica infection $\left(5 \times 10^{4} \mathrm{CFU}\right)$ in the mouse. Although the mechanism needs to be elucidated, this study suggests that activation of coagulation during infection induces innate responses that further activate multiple coagulation pathways. Thus, activation of the coagulation cascade might be required for an efficient host immune response against some Gram-negative bacteria (72). Collectively, these studies demonstrate the close relationship between bacterial pathogens, hemostasis and coagulation and offer tantalizing evidence that thrombi can help restrict bacterial dissemination.

Based on these studies, it is important to recognize that not all the infections are the same and that the role of coagulation during bacterial infections can vary in a pathogenand dose-dependent manner. Understanding how pathogens, coagulation and inflammation interact will allow exploration of alternative therapeutic targets that offer better outcomes than the current ones.

\section{SALMONELLA INFECTIONS OF MICE: A MODEL TO EVALUATE THE INDUCTION AND RESOLUTION OF INFECTION-MEDIATED THROMBOSIS}

\section{Salmonella spp. and the Infection They Cause}

Salmonella enterica (S. enterica) are gram-negative, facultative intracellular microorganisms that cause hundreds of thousands of deaths each year, with risk of death increasing markedly when bacteria invade systemically. There are more than 2,500 serovars of $S$. enterica, and these can infect a wide range of species, including humans, other mammals, and livestock. Many human infections are zoonotic in origin, such as those caused by the serovars $S$. Typhimurium (STm) and $S$. Enteritidis (SEn), though some serovars, such as S. Typhi, or S. Paratyphi A-C, the causative agents of enteric fever, are human-restricted. Nontyphoidal Salmonellae (NTS), such as STm and SEn, typically cause acute, self-limiting gastrointestinal infections. However, malnutrition, immunodeficiencies and co-infection with malaria or HIV, increase the risk of acquiring invasive non-typhoidal salmonellosis (iNTS), which is a systemic infection with high mortality rates of up to $25 \%$ (86).

A relationship between typhoid and thrombosis has been known for over a century $(87,88)$. There are also several reports of cases where patients infected with Salmonella present with thrombosis as a complication (89-93). Thrombosis caused by Salmonella infections has also been reported in animals, such as calves (94), rats (95), and hamsters (96). Collectively, such studies demonstrate that Salmonella infections are able to induce thrombosis in a broad range of animal hosts.

\section{Mouse Models of Salmonella Infection}

STm infection of mice is a promising model for studying thrombosis development and resolution during infection. When injected into mice, STm induces an infection that resembles invasive disease (aspects of enteric fever and iNTS). STm can be given i.v., i.p., or orally, and mice from different genetic backgrounds can be used. The mouse model of STm infection has one major advantage over many other bacterial infection models-mice can be infected with sufficient numbers of bacteria to induce quite marked and prolonged clinical signs, but the mouse will ultimately resolve the infection over a period of weeks.

In mice, susceptibility to Salmonella infection is associated with the gene Solute Carrier Family 11 Member 1 (Slc11a1), which encodes for the natural resistance-associated macrophage protein 1 (hereafter referred to as Nramp1). Nramp1 transports divalent cations out of the phagosomes, which interferes with the function of bacterial enzymes required for the survival of many intracellular pathogens, including Salmonella (97-99). A single point-mutation in Nramp1 markedly reduces the $\mathrm{LD}_{50}$ (Lethal Dose, 50\%) of a mouse to virulent STm $>1,000$-fold. Therefore, it is important to consider the bacterial strain, the mouse strain and the route of infection in this model. Mouse strains with a missense mutation in Nramp1 include the commonly used $\mathrm{C} 57 \mathrm{BL} / 6 \mathrm{~J}$ and $\mathrm{BALB} / \mathrm{c}$ strains, the background for most genetically-altered mice. Infection of these strains either i.p. or i.v. with $<10 \mathrm{CFU}$ of a virulent STm strain (e.g., the commonly used laboratory strain SL1344) leads to an acute and systemic infection with bacteremia, where bacteria reach $\geq 10^{6} \mathrm{CFU} / \mathrm{mL}$ blood, and is fatal in $<7$ days. In contrast, resistant strains with functional Nramp1, such as CD1 and Sv129S6 strains, are more resistant to infection with this strain, are able to clear or develop long-term chronic colonization (99). Susceptible mouse strains can be infected orally with higher numbers of virulent bacteria, but if the infection goes systemic then a similar outcome to i.v. infection will be observed.

Few genetically-altered mice are on resistant backgrounds, which can limit the possibility to perform longer-term 
mechanistic studies without undertaking expensive and time consuming backcrossing of mice. Such limitations can partly be overcome by infecting susceptible mice i.p. or i.v. with attenuated STm [e.g., aroA-deficient SL3261 (100)]. Using such bacteria, it is possible to inoculate with higher bacterial doses (typically $10^{5}-10^{6}$ bacteria) per mouse, with the infection resolving over a period of months [e.g., $(101,102)]$. After infecting susceptible mice with this dose either i.p. or i.v., bacteria can be retrieved from the bone marrow, brain, kidneys and lungs, but the organs with the highest bacterial burdens are the spleen and liver (74). In both organs, bacterial numbers peak at the end of the first week and fall gradually from the third week post-infection, to ultimately be cleared by around 8 weeks (101), and co-infection can influence the rate of clearance (103).

The inflammatory cell response that follows STm infection is dominated by monocytes and neutrophils. At $24 \mathrm{~h}$ after i.p. infection of C57BL6/J mice with attenuated STm, we have found that in the spleen, there is an increase of in the total number of Ly6C + monocytes (104). Additionally, Tam et al. have shown that, after intragastric administration of the bacteria, at 7 days post-infection, there was an increase in the total

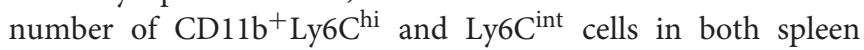
and liver (105). Infection with STm also induces inflammation in the liver. However, this is organized in granuloma-like structures, often referred to as inflammatory foci. These foci consist mainly of $\mathrm{F} 4 / 80^{+}$cells and have been shown to be sites of bacterial containment (106). Neutrophils have been detected in the peritoneum of infected mice as early as $12 \mathrm{~h}$ post-injection (107) and they have shown to accumulate in sites of infection, such as spleen and liver (105). Together these studies suggest that there are contributions from tissue-resident and migratory innate immune cells to the inflammatory response after STm infection in different tissues. This can help explain why there are different inflammatory responses at different sites at different times after infection that in turn may impact on the response to the bacteria.

\section{Thrombosis and Salmonella Infection in Mice}

Thrombosis induced after STm infection has been reported in both resistant and susceptible strains of mice after infection with virulent and attenuated strains of bacteria, respectively. After infecting Sv129S6 mice orally with a virulent strain of STm (SL1344), Brown et al described the development of hepatic microthrombi after the first week of infection, followed by a more extensive thrombosis in the spleen and liver at 3 weeks post-infection (84). Furthermore, venous thrombosis in the livers of mice can be observed months after infection, although levels were not quantified, meaning it is difficult to judge their prevalence long-term (108). Moreover, in a mouse that died from infection, there was a marked thrombosis in the spleen and liver, suggesting that this correlates with disease severity. Vaccination can reduce the level of thrombosis induced (109). Furthermore, a model to study Salmonella-associated meningitis demonstrated that this infection can induce thrombosis in the brain (110).

\section{Thrombosis After STm Infection Is Driven by Inflammation}

Our own interest in studying thrombosis after STm infection came from our observations on the effects of STm infection on immune cell populations and host immune homeostasis. Using a model of infection of susceptible mice with attenuated STm we had identified how infection altered the functioning of sites such as the bone marrow and thymus $(111,112)$. When we examined the response in the liver (74), it was dramatically different to control mice. By 7 days after infection, there was a substantial recruitment of monocytes into inflammatory foci accompanied by the parallel presence of an extensive thrombosis. Thrombi were overwhelmingly restricted to the hepatic portal vein, were white in appearance and contained mainly platelets, fibrin, and immune cells. They were typically observed at sites of endothelial perturbation. Additionally, the levels of thrombosis and inflammatory foci in the liver are maintained at their peak levels between 1 and 3 weeks post-infection despite bacterial numbers in the organ falling by $90-99 \%$ during this time and bacteremia not being detected. The link between inflammation and thrombosis was confirmed by studies that showed that after infection of mice deficient in TLR4 or IFN $\gamma$, there was a near absence of both thrombosis and inflammatory foci. This supports the concept that thrombosis is triggered by the infection but driven by the inflammatory response (74).

The association between disturbed endothelial integrity and thrombus development suggests that thrombi form after contact with sub-endothelial cells or other factors that are absent in healthy tissues. In the liver, STm infection induces the upregulation of podoplanin in inflammatory foci and podoplanin can bind C-type lectin-like receptor 2 (CLEC2) that is expressed on platelets and can mediate platelet activation (113). Transgenic mice lacking CLEC-2 on platelets and megakaryocytes (PF4.Cre-Clec-Ib ${ }^{\mathrm{fl} / \mathrm{fl}}$ ) had much lower levels of thrombosis, indicating that CLEC-2-podoplanin ligation drove platelet activation and subsequently thrombosis (74). Loss of CLEC-2 expression in these cells did not significantly alter bacterial clearance or the capacity to drive inflammatory foci development. Furthermore, treatment of mice with clodronate liposomes, which reduces numbers of macrophage/monocytic cells, abrogated the development of thrombosis in infected mice. Therefore, using the murine model of STm infection, a novel mechanism of infection-mediated thrombosis was identified (74).

\section{Infection Can Develop in Spleen and Liver With Discordant Kinetics}

Our original studies had focused on the liver since at day 7 post-infection thrombosis was extensive in this organ, with thrombi located in the portal vein. Parallel assessment of the spleen, which has a similar peak bacterial burden and rate of clearance, had not identified such an extensive thrombosis and so it was initially considered that the liver was the major site where this developed. Thus, it was unexpected when we observed that in the same model of infection a widespread thrombosis was detected in the spleen $24 \mathrm{~h}$ after infection, with thrombi 
localized to the splenic vein (104). In both organs, thrombi are not detected to any significant degree in the arterial system. It should be noted that to observe thrombi, particularly in the bigger vessels, then it is important to section deeply into the tissues, and since the spleen can increase in size $>10$-fold postinfection, this is can be technically challenging. In the spleen, it is optimal to section longitudinally to the hilum to ensure better representation of the splenic vein on a section. Thrombosis in the spleen was transient since thrombus numbers and size had fallen dramatically by $48 \mathrm{~h}$ post-infection and remained low thereafter. Therefore, thrombosis can occur in different organs at different times post-infection despite both those organs containing similar bacterial burdens. Another lesson we can learn from this is that the resolution of thrombosis, at least in the spleen, does not require a fall in bacterial numbers inside an organ, since in this model, bacterial numbers are stable or rising in the first days after infection (104).

The mechanism of thrombosis in the spleen is less explored. Phagocytic cells such as monocytes/macrophages play an important role, since depletion of these cells by clodronate treatment prior to infection, resulted in a significant reduction in numbers of thrombi in the spleen (104). The exact contribution of different monocytic-lineage cells to this process is currently unknown, but with subpopulations of such cells occupying distinct niches in the spleen such as the red pulp or marginal zone, it is possible that each subpopulation make distinct

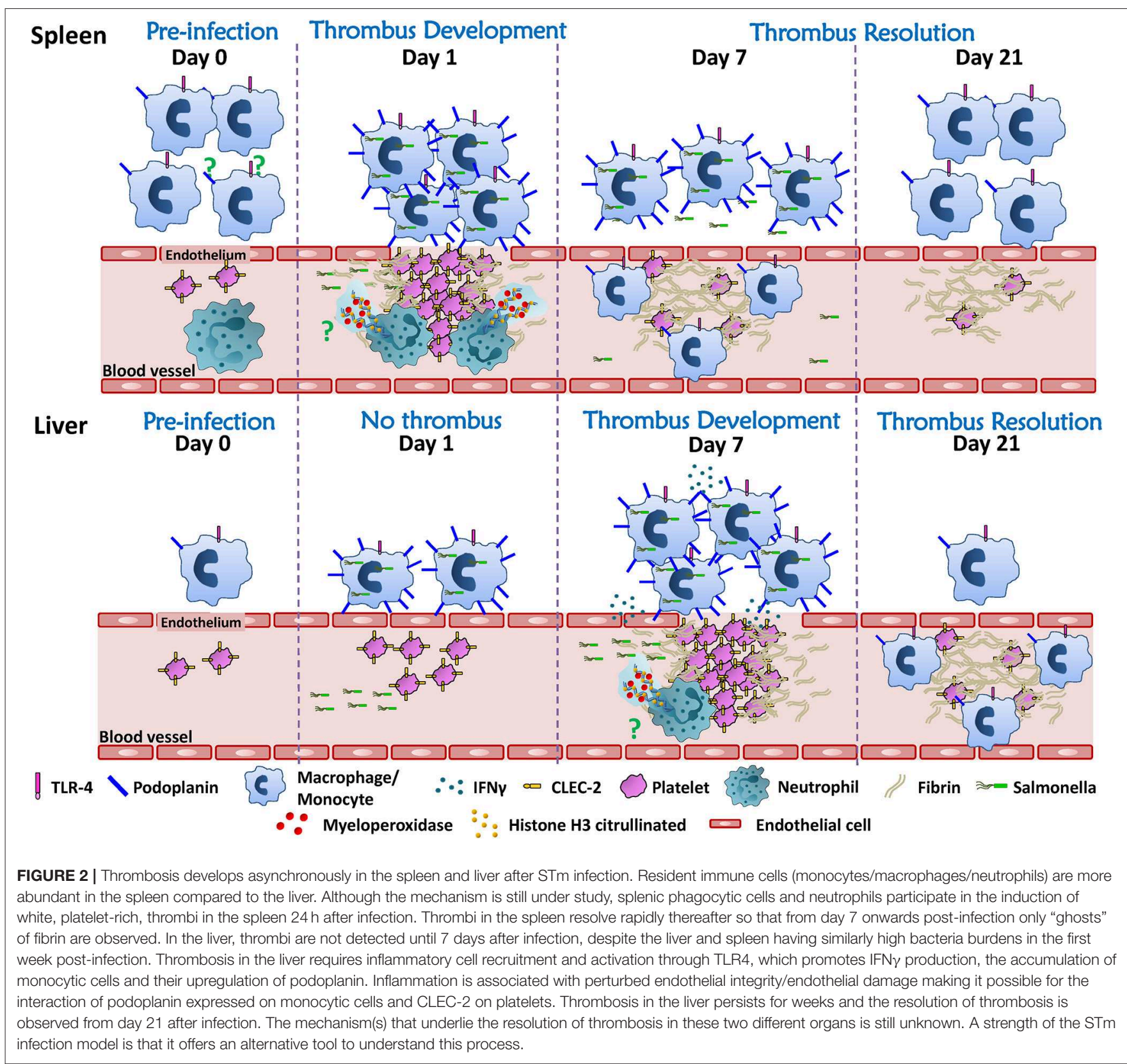


contributions to this process. However, the fact that thrombosis in the spleen follows such a discordant kinetics compared to the liver, both in induction and resolution, suggests that there may be additional site-specific mechanisms involved, as summarized in Figure 2. An additional contribution to the risk of thrombosis in different sites may be the level of local endothelial activation, but this has not been explored in great depth. Further experiments exploring the cellular requirements and the cytokines that may contribute to the establishment of thrombosis in the spleen are currently undergoing. Details revealed using longer-term infection models such as STm could help us understand the relationship between thrombosis and infection within a specific organ, or alternatively, the findings may only be specific to STm infections. This could ultimately help us identify how to predict where thrombosis will develop for a specific infection, if the agent is unknown or if no agent is identified then it might still be possible to predict sites of thrombosis if the same mechanisms are conserved in other systems. A second implication is that if there are multiple, site-specific mechanisms active to the same pathogen, and this holds true for multiple infections, then it may have significant implications for trying to control thrombosis. This is because it would imply that a single, one-size-fits-all approach to treatment is not likely to be useful in all cases, and may help explain the limited success observed in controlling infection-associated thrombosis to date. Thus, it is likely to be important to study the kinetics of thrombosis in multiple organs to understand all the mechanisms for triggering thrombosis and its resolution.

An interesting contrast between the Salmonella model and that of other bacterial infection models is the timing when thrombosis is detected. As described above, in most bacterial infection models using Gram-positive or negative bacteria thrombosis is detected in the first minutes or hours after infection, rather than much later for Salmonella. This indicates the importance in identifying the most appropriate model to use to address the researchers scientific question. Nevertheless, it is possible that infection with STm can induce thrombi this rapidly, and such effects may be more readily identifiable with infection at higher doses of bacteria than those typically used, but we have not been able to identify a report where this has been done. Microthrombi in the liver have been reported, presumably arterial, in mice one week after infection, but their location was not specified (84). Potential reasons for the striking differences in timing are worth considering. The later onset may simply reflect the non-lethality of the Salmonella model when used as typically described in the literature, meaning productive infections are active for longer. The numbers of Salmonella given are relatively low, typically $<1 \%$, compared to the number of E. coli bacteria typically given, and so it may take longer for thrombosis to be induced. If other bacterial infections could persist to similar levels, and for as long as Salmonella, then perhaps a similar pattern of thrombosis would be observed. Indeed, there are many examples of cases of thrombosis that occur in humans and primates when the infection is known to have been established for days. For instance, in a primate model of pneumonic plague, where death occurred between 3 and 7 days post-challenge, then widespread thrombosis was detected in the kidneys, similar to what has been described elsewhere for natural Salmonella infections in hamsters $(96,114)$. The temporal window for detecting thrombi detailed in these examples and for STm in the mouse show some overlap, indicating that thrombosis can occur at similar times in other model systems and so may be reasonably common. Nevertheless, there needs to be caution in taking these analogies further, which ultimately highlights the need for further studies in animal models and in humans. Although, the observations in mice after STm infection may be analogous to what is observed elsewhere after long-term infection, it still remains possible that the murine model of salmonellosis is unique, or atypical. Furthermore, the nature of the thrombi themselves needs to be considered. Typically, thrombi that form in the venous vasculature commonly are rich in erythrocytes, and often termed "red thrombi." In contrast, thrombi in the arterial circulation mostly contain platelets and are referred to as "white thrombi." After STm infection in mice, the thrombi are white, yet located in the venous circulation. What this actually signifies is unclear, and the composition of thrombi post-infection is not particularly well documented even in reviews of autopsies on septic patients (115), despite its importance for directing appropriate treatment (116). All of these points indicate the need for further work to understand the relationship between inflammatory cells in the parenchyma, platelets, and the vessels where thrombi form.

\section{Thrombi in Mice After STm Infection Contain Few Bacteria}

The development of techniques to identify bacteria in infected tissues has enabled us to address directly what level of bacterial load is found in individual thrombi. Based on previous studies (e.g., see above), we had anticipated that there would be significant burdens within each thrombus. Thus, it was unexpected to find that most thrombi contain few or no bacteria. This was the case if splenic or liver thrombi were examined or whether this was early or later after infection (104). This is unlikely to reflect bacteria being rapidly killed and cleared as the methodology used detects antigen and not live bacteria, and there is no difference in the level of detection of bacterial antigen in the splenic thrombi, where thrombosis occurs in a highly synchronized manner, or in the liver, where thrombosis is more protracted. In contrast to this lack of detection of bacteria in thrombi, bacteria were widespread throughout the tissues and always easy to identify. This would suggest that thrombi induced after infection are not always able to act as efficient bacterial traps. Indeed, it could be possible that in many instances trapping bacteria is not a key consequence of the induction of thrombi after infection.

\section{CURRENT AND POTENTIAL THERAPEUTIC TARGETS FOR INFECTION-INDUCED THROMBOSIS}

The potential harm caused by thrombosis during infection, and its long-term consequences, has led to it being a target for therapies that either prevent or limit infection-associated 
thrombosis. Although patients with sepsis will generally receive low molecular weight heparin to prevent DVT/PE there is no current antithrombotic treatment schemes used specifically for patients with infection. Despite the significant attention this area has received, no optimal approach has yet been identified. In this last section, we briefly discuss antithrombotic approaches so far tested, before introducing new potential targets for treating infection-driven thrombosis (Figure 3). The ideal treatment profile would include the capacity to target thrombosis, but not increase the risk of bleeding or worsening infection.

\section{Coagulation and Fibrinolysis}

Anticoagulants have been used during sepsis-induced coagulopathy due to evidence of perturbed levels of proand anticoagulant factors in sepsis. The aim is to restore plasma levels of the coagulation factors consumed during sepsis (117). Among the factors so far tested are antithrombin (AT) which blocks thrombin along with other clotting factors (Xa, IXa, VIIa, XIa, and XIIa), thus interfering with fibrin conversion (118). Recombinant TFPI (rTFPI) has been used to block the activation of factor X by Factor VIIa-TF complex, preventing spontaneous activation of coagulation (118). Thrombomodulin (TM) recombinant protein has been used in sepsis to reduce coagulation through binding to thrombin and enhancing protein C activation (119). Activated protein C (APC) targets inflammation and coagulation pathways, inhibiting factors $\mathrm{Va}$ and VIIIa to reduce thrombin generation and degrade histones from NETs (118). Recombinant tissue plasminogen activator (tPA) has been used for facilitating thrombus clearance, increasing fibrinolysis during venous thromboembolism, but with limited use in infection-induced coagulopathies (120-123). However, despite these approaches being based on high quality science, all of the anticoagulant recombinant proteins failed to demonstrate a significant benefit during clinical trials and also increased the bleeding risk (124-128). Currently, the use of heparin is attracting significant attention as its activity is associated with relatively low risk of bleeding (129). Heparin targets coagulation through the binding and activation of AT to inhibit thrombin and other clotting factors (IIa and Xa) $(118,130)$. Moreover, heparin can also limit inflammation

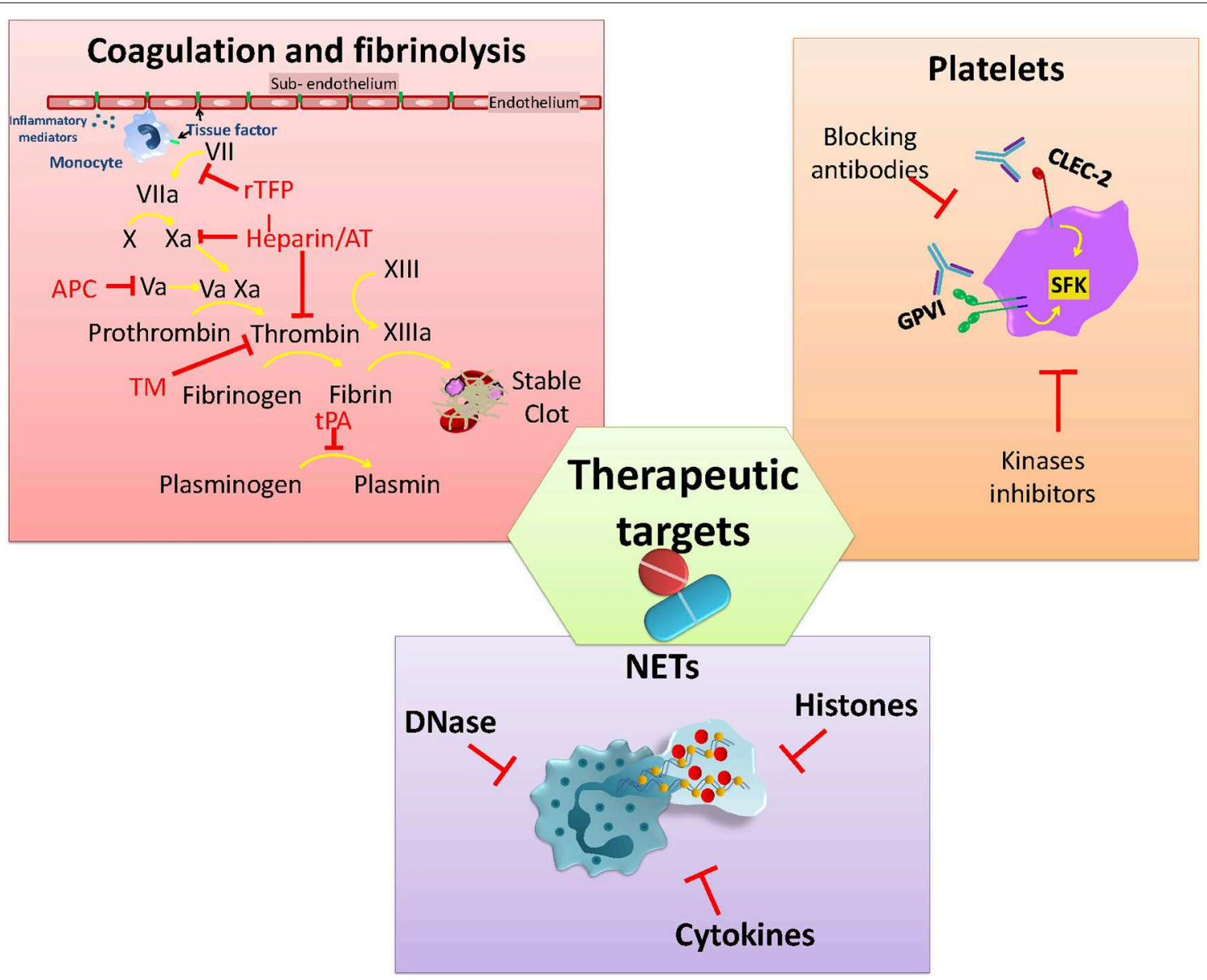

FIGURE 3 | Current and potential molecules or pathways to target infection-associated thrombosis. Anticoagulants interfere with the activity of different clotting factors in the coagulation cascade that aims to rebalance hemostasis. Platelet GPVI and CLEC-2 are activated via SFK kinases and play a role in infection-mediated platelet activation. Neutrophil activation and the release of NETs together with associated factors (DNA/Histones) are also under study for developing strategies to limit their pro-thrombotic effects. 
by disrupting NETs through interactions with histones (131). Heparin use is widely used for the prevention and treatment of thromboembolic events in many circumstances (130). No published studies have evaluated the use of heparin to limit thromboembolic complications associated with infection.

\section{Inhibiting Platelet Activity}

Platelet activation plays a crucial role not only in infectiondriven thrombosis but also during the immune response against pathogens (132). Both infection and inflammation can directly or indirectly activate platelets through different receptors, triggering aggregation and thrombi formation within the vasculature $(132,133)$. In addition to this, there are some receptors that have attracted the attention of researchers due to their participation in thrombo-inflammation events. Glycoprotein VI (GPVI) and CLEC-2 are two platelets receptors that play roles during infection, either directly in the pathogen response or in infection-driven thrombosis $(52,74,134,135)$. GPVI mediates platelet activation by collagen but it also binds to a number of additional endogenous and exogenous ligands including laminin, fibronectin, adiponectin, toxins, and polysulfated sugars (136). Activation of GPVI has been associated with a protective role during $K$. pneumoniae-induced pneumosepsis through promoting platelet-leukocyte aggregates and enhancing bacteria phagocytosis in vitro (134). CLEC-2 interacts with podoplanin, which is expressed by many cell types including podocytes, lymphatic and lung epithelial cells, and inflammatory macrophages (137). As mentioned previously, CLEC-2/podoplanin interactions play an important role in thrombosis in the liver after STm infection of mice (74). Moreover, either genetically deleting or blocking the CLEC2/podoplanin axis with monoclonal antibodies has shown a reduction in thrombus formation in a mouse model of DVT (138). Similar outcomes are reported in an ARDS mouse model (139) where treating mice with an anti-podoplanin antibody improves the response by altering the cytokine production and cell recruitment. In contrast, CLEC-2-deficiency worsens outcome in the CLP model (52) associated with increased levels of pro-inflammatory cytokines, reduced macrophage recruitment to the peritoneum and higher bacterial numbers at this site. Thus, CLEC-2 and GPVI are potential therapeutic targets for infection-associated thrombosis that would have a limited impact on hemostasis.

Alongside blocking extracellular receptors to inhibit platelet activation, targeting signaling pathways involved in thromboinflammation has been proposed as an alternative approach to tackle inflammation-induced coagulation (140). Signaling through tyrosine kinases such as the Tec kinase Bruton-tyrosine kinase (Btk), members of the Src family of kinases (SFK) (Syk, Fyn, Lyn), and spleen activated kinase (Syk) is essential for regulation of hemostatic and inflammatory processes (141). All three families are highly expressed by platelets and leukocytes and have essential role in activation, adhesion, recruitment and effector responses. On platelets, GPVI and CLEC-2 receptors are activated via (hemi)ITAM phosphorylation through Src, Syk, and Tec kinases, making this pathway an attractive target for blocking platelet activation (141-144). However, inhibiting the Btk pathway can be a double-edge sword during infection, since these kinases are also needed for an efficient immune response. Finding the balance to limit platelet activation without affecting the immune response and without increasing the risk of bleeding is the biggest challenge for developing new treatments to prevent or to limit thrombosis under infectiondriven inflammatory conditions.

\section{Neutrophil Activation}

Platelets express a wide range of classical immune receptors such as TLRs (145). Activation of TLR4 with LPS promotes binding of platelets to neutrophils and can promote NET formation (146). The involvement of platelets in promoting NETs has been described in in vivo models of sepsis and viral infection $(133,147)$. In an E. coli-induced sepsis model, NETs within the microvasculature could help trap bacteria, yet their induction also increased organ damage and promoted thrombosis through a NET-platelet-thrombin pathway (148). This is due to the many NET-derived elements that have procoagulant properties, including histones, DNA, and proteases that can activate coagulation through either the extrinsic or intrinsinc pathway (148). PAD4 $4^{-/}$mice do not generate NETs after systemic bacterial exposure in the CLP model. Despite this, PAD4 ${ }^{-/-}$mice control the infection to the same level as wildtype, but experience lower levels of inflammation and thrombosis (149). Although PAD4 is essential for the development of NETs, it is dispensible for NET formation once the process has started (149). Thus, blocking PAD4 may be a prophylactic way to target NET development, but is unlikely to be a therapeutic route. To achieve this, it may be necessary to block the whole PAD pathway. Since increased free DNA from NETs contributes to vascular occlusion it means targeting NETs with DNases may be a route to protect against the harmful effects of NETosis (150). However, the timing of when to inhibit NETs is likely to be important. Administration of DNase during the early stages of CLP ( $2 \mathrm{~h}$ after surgery) is detrimental, resulting in enhanced levels of inflammatory cytokines. In contrast, delaying treatment with DNase to 4-6h after puncture can improve the clinical score and bacteria control (151). STm infection can stimulate NETs in vitro and these NETs can trap bacteria (152). Nevertheless, the role of neutrophils and NETs in thrombosis after infection has not been described.

\section{CONCLUSION}

Infection-mediated thrombosis links the inflammatory response induced in response to the pathogen with the coagulation system. Further research that uses longer-term infection models may help elucidate the full consequences of driving thrombosis and the wider mechanisms behind thrombus development. The numbers of models available are limited and may not fully represent the events experienced by humans during severe infections. Nevertheless, addressing the areas where we have a limited understanding of the drivers and consequences of infection-driven thrombosis will help us develop better strategies to prevent and treat thromboembolic complications without compromising the immune response against the pathogen or interfere with hemostasis. 


\section{AUTHOR CONTRIBUTIONS}

NB-C contributed to the conception of the study, writing the manuscript, and generating the figures. MP-T contributed to writing the manuscript. MT proof-read the manuscript and contributed to the intellectual concepts. IH proof-read the manuscript. SW proof-read the manuscript and contributed to the intellectual concepts. AC co-wrote the manuscript and contributed to the intellectual concepts within the manuscript.

\section{REFERENCES}

1. Smeeth L, Cook C, Thomas S, Hall AJ, Hubbard R, Vallance P. Risk of deep vein thrombosis and pulmonary embolism after acute infection in a community setting. Lancet. (2006) 367:1075-9. doi: 10.1016/S0140-6736(06)68474-2

2. Dalager-Pedersen M, Sogaard M, Schonheyder HC, Nielsen H, Thomsen RW. Risk for myocardial infarction and stroke after community-acquired bacteremia: a 20-year population-based cohort study. Circulation. (2014) 129:1387-96. doi: 10.1161/CIRCULATIONAHA.113.006699

3. Cohoon KP, Ashrani AA, Crusan DJ, Petterson TM, Bailey KR, Heit JA. Is infection an independent risk factor for venous thromboembolism? A population-based, case-control study. Am J Med. (2018) 131:307-16.e2. doi: 10.1016/j.amjmed.2017.09.015

4. Liu X, Wang L, Wang S, Zhang W, Yu Y, Chen S, Ao H. Association between infection and thrombosis after coronary artery bypass grafting: a cohort study. J Cardiothorac Vasc Anesth. (2019) 33:1610-6. doi: 10.1053/j.jvca.2018.09.008

5. Fugate JE, Lyons JL, Thakur KT, Smith BR, Hedley-Whyte ET, Mateen FJ. Infectious causes of stroke. Lancet Infect Dis. (2014) 14:869-80. doi: 10.1016/S1473-3099(14)70755-8

6. Huang J. Infection and thrombosis in cardiac surgery: is there a common ground? J Cardiothorac Vasc Anesth. (2019) 33: 1617-9. doi: $10.1053 /$ j.jvca.2018.10.003

7. Dolapsakis C, Kranidioti E, Katsila S, Samarkos M. Cavernous sinus thrombosis due to ipsilateral sphenoid sinusitis. BMJ Case Rep. (2019) 12:e227302. doi: 10.1136/bcr-2018-227302

8. Oliveira GN, Basso S, Sevivas T, Neves N. Varicella complicated by cellulitis and deep vein thrombosis. BMJ Case Rep. (2017) 2017:bcr-2017-221499. doi: 10.1136/bcr-2017-221499

9. Kohler JA, Munoz FM, Goss JA, Miloh TA. Viral upper respiratory infection at pediatric liver transplantation is associated with hepatic artery thrombosis. Liver Transpl. (2017) 23:1477-81. doi: 10.1002/lt.24866

10. Ceccarelli M, Venanzi Rullo E, Nunnari G. Risk factors of venous thrombo-embolism during cytomegalovirus infection in immunocompetent individuals. A systematic review. Eur J Clin Microbiol Infect Dis. (2018) 37:381-90. doi: 10.1007/s10096-018-3185-y

11. Edula RG, Qureshi K, Khallafi H. Acute cytomegalovirus infection in liver transplant recipients: An independent risk for venous thromboembolism. World J Hepatol. (2013) 5:692-5. doi: 10.4254/wjh.v5.i12.692

12. Samarasekara K, Munasinghe J. Dengue shock syndrome complicated with acute liver failure and kidney injury, infective endocarditis, and deep vein thrombosis: a case report. J Med Case Rep. (2018) 12:321. doi: 10.1186/s13256-018-1862-1

13. Roquer J, Cuadrado-Godia E, Giralt-Steinthauer E, Jimena S, JimenezConde J, Martinez-Rodriguez JE, et al. Previous infection and stroke: a prospective study. Cerebrovasc Dis. (2012) 33:310-5. doi: 10.1159/0003 35306

14. Corrales-Medina VF, Madjid M, Musher DM. Role of acute infection in triggering acute coronary syndromes. Lancet Infect Dis. (2010) 10:83-92. doi: 10.1016/S1473-3099(09)70331-7

15. Leinonen M, Saikku P. Evidence for infectious agents in cardiovascular disease and atherosclerosis. Lancet Infect Dis. (2002) 2:11-7. doi: 10.1016/S1473-3099(01)00168-2

\section{FUNDING}

This work was supported by grants from the Medical Research Council (MR/N023706/1) and the British Heart Foundation (BHF) (RG/13/18/30563). NB-C was supported by National Council of Science and Technology (CONACYT)-Mexico overseas postdoctoral fellowship (CVU 332390). SW is a BHF Chair $(\mathrm{CH} / 03 / 003)$. Open access publication fees are covered by University of Birmingham.

16. Musher DM, Abers MS, Corrales-Medina VF. Acute infection and myocardial infarction. $N$ Engl J Med. (2019) 380:171-6. doi: 10.1056/NEJMra1808137

17. Franchi T, Eaton S, De Coppi P, Giuliani S. The emerging role of immunothrombosis in paediatric conditions. Pediatr Res. (2019) 86:19-27. doi: 10.1038/s41390-019-0343-6

18. Ferguson JH, Chapman OD. Fulminating meningococcic infections and the so-called Waterhouse-Friderichsen syndrome. Am J Pathol. (1948) 24:76395.

19. Margaretten W, Mc AA. An appraisal of fulminant meningococcemia with reference to the Shartzman phenomenon. Am J Med. (1958) 25:868-76. doi: 10.1016/0002-9343(58)90059-7

20. Heyderman RS. Sepsis and intravascular thrombosis. Arch Dis Child. (1993) 68:621-3. doi: 10.1136/adc.68.5.621

21. Buras JA, Holzmann B, Sitkovsky M. Animal models of sepsis: setting the stage. Nat Rev Drug Discov. (2005) 4:854-65. doi: 10.1038/nrd1854

22. Ho LWW, Kam P, Thong CL. Disseminated intravascular coagulation. Curr Anesth Critic Care. (2005) 16:151-61. doi: 10.1016/j.cacc.2005.03.011

23. Tani VM, Assis-Mendonca GR, da Silva TB, Rogerio F, De Paula EV. Microvascular thrombosis in sepsis: an autopsy study. Thromb Res. (2017) 156:23-5. doi: 10.1016/j.thromres.2017.05.031

24. Mauriello A, Sangiorgi G, Fratoni S, Palmieri G, Bonanno E, Anemona $\mathrm{L}$, et al. Diffuse and active inflammation occurs in both vulnerable and stable plaques of the entire coronary tree: a histopathologic study of patients dying of acute myocardial infarction. J Am Coll Cardiol. (2005) 45:1585-93. doi: 10.1016/j.jacc.2005.01.054

25. Xu J, Zhang X, Pelayo R, Monestier M, Ammollo CT, Semeraro F, et al. Extracellular histones are major mediators of death in sepsis. Nat Med. (2009) 15:1318-21. doi: 10.1038/nm.2053

26. Lahteenmaki K, Kukkonen M, Korhonen TK. The Pla surface protease/adhesin of Yersinia pestis mediates bacterial invasion into human endothelial cells. FEBS Lett. (2001) 504:69-72. doi: 10.1016/S0014-5793(01)02775-2

27. Coleman JL, Gebbia JA, Piesman J, Degen JL, Bugge TH, Benach JL. Plasminogen is required for efficient dissemination of B. burgdorferi in ticks and for enhancement of spirochetemia in mice. Cell. (1997) 89:1111-9. doi: 10.1016/S0092-8674(00)80298-6

28. Lahteenmaki K, Kuusela P, Korhonen TK. Bacterial plasminogen activators and receptors. FEMS Microbiol Rev. (2001) 25:531-52. doi: 10.1111/j.1574-6976.2001.tb00590.x

29. Lee WY, Moriarty TJ, Wong CH, Zhou H, Strieter RM, van Rooijen N, et al. An intravascular immune response to Borrelia burgdorferi involves Kupffer cells and iNKT cells. Nat Immunol. (2010) 11:295-302. doi: 10.1038/ni.1855

30. Fuchs TA, Brill A, Duerschmied D, Schatzberg D, Monestier M, Myers DD Jr., et al. Extracellular DNA traps promote thrombosis. Proc Natl Acad Sci USA. (2010) 107:15880-5. doi: 10.1073/pnas.1005743107

31. Massberg S, Grahl L, von Bruehl ML, Manukyan D, Pfeiler S, Goosmann C, et al. Reciprocal coupling of coagulation and innate immunity via neutrophil serine proteases. Nat Med. (2010) 16:887-96. doi: 10.1038/nm.2184

32. Berthelsen LO, Kristensen AT, Tranholm M. Animal models of DIC and their relevance to human DIC: a systematic review. Thromb Res. (2011) 128:103-16. doi: 10.1016/j.thromres.2010.12.002

33. Cohen J. The immunopathogenesis of sepsis. Nature. (2002) 420:885-91. doi: $10.1038 /$ nature 01326 
34. Pawlinski R, Pedersen B, Schabbauer G, Tencati M, Holscher T, Boisvert W, et al. Role of tissue factor and protease-activated receptors in a mouse model of endotoxemia. Blood. (2004) 103:1342-7. doi: 10.1182/blood-2003-09-3051

35. Yanada M, Kojima T, Ishiguro K, Nakayama Y, Yamamoto K, Matsushita $\mathrm{T}$, et al. Impact of antithrombin deficiency in thrombogenesis: lipopolysaccharide and stress-induced thrombus formation in heterozygous antithrombin-deficient mice. Blood. (2002) 99:2455-8. doi: 10.1182/blood.V99.7.2455

36. Hermida J, Montes R, Paramo JA, Rocha E. Endotoxin-induced disseminated intravascular coagulation in rabbits: effect of recombinant hirudin on hemostatic parameters, fibrin deposits, and mortality. J Lab Clin Med. (1998) 131:77-83. doi: 10.1016/S0022-2143(98)90080-4

37. Levi M, Dorffler-Melly J, Reitsma P, Buller H, Florquin S, van der Poll T, Carmeliet P. Aggravation of endotoxin-induced disseminated intravascular coagulation and cytokine activation in heterozygous protein-C-deficient mice. Blood. (2003) 101:4823-7. doi: 10.1182/blood-2002-10-3254

38. Xiang B, Zhang G, Guo L, Li XA, Morris AJ, Daugherty A, et al. Platelets protect from septic shock by inhibiting macrophage-dependent inflammation via the cyclooxygenase 1 signalling pathway. Nat Commun. (2013) 4:2657. doi: 10.1038/ncomms3657

39. Armstrong MT, Rickles FR, Armstrong PB. Capture of lipopolysaccharide (endotoxin) by the blood clot: a comparative study. PLoS ONE. (2013) 8:e80192. doi: 10.1371/journal.pone.0080192

40. Engelmann B, Massberg S. Thrombosis as an intravascular effector of innate immunity. Nat Rev Immunol. (2013) 13:34-45. doi: 10.1038/nri3345

41. Berube BJ, Bubeck Wardenburg J. Staphylococcus aureus $\alpha$-toxin: nearly a century of intrigue. Toxins (Basel). (2013) 5:1140-66. doi: 10.3390/toxins5061140

42. Parimon T, Li Z, Bolz DD, McIndoo ER, Bayer CR, Stevens DL, et al. Staphylococcus aureus $\alpha$-hemolysin promotes platelet-neutrophil aggregate formation. J Infect Dis. (2013) 208:761-70. doi: 10.1093/infdis/jit235

43. Surewaard BGJ, Thanabalasuriar A, Zeng Z, Tkaczyk C, Cohen TS, Bardoel BW, et al. $\alpha$-Toxin induces platelet aggregation and liver injury during staphylococcus aureus sepsis. Cell Host Microbe. (2018) 24:271-84.e3. doi: 10.1016/j.chom.2018. 06.017

44. Fortier ME, Kent S, Ashdown H, Poole S, Boksa P, Luheshi GN. The viral mimic, polyinosinic:polycytidylic acid, induces fever in rats via an interleukin-1-dependent mechanism. Am J Physiol Regul Integr Comp Physiol. (2004) 287:R759-66. doi: 10.1152/ajpregu.00293.2004

45. Antoniak S, Tatsumi K, Bode M, Vanja S, Williams JC, Mackman N. Protease-activated receptor 1 enhances poly i:c induction of the antiviral response in macrophages and mice. J Innate Immun. (2017) 9:181-92. doi: $10.1159 / 000450853$

46. D’Atri LP, Etulain J, Rivadeneyra L, Lapponi MJ, Centurion M, Cheng K, et al. Expression and functionality of Toll-like receptor 3 in the megakaryocytic lineage. J Thromb Haemost. (2015) 13:839-50. doi: 10.1111/jth.12842

47. Blum P, Pircher J, Merkle M, Czermak T, Ribeiro A, Mannell H, et al. Arterial thrombosis in the context of $\mathrm{HCV}$-associated vascular disease can be prevented by protein C. Cell Mol Immunol. (2017) 14:986-96. doi: $10.1038 / \mathrm{cmi} .2016 .10$

48. Levi M, Ten Cate H. Disseminated intravascular coagulation. N Engl J Med. (1999) 341:586-92. doi: 10.1056/NEJM199908193410807

49. Angus DC, van der Poll T. Severe sepsis and septic shock. $N$ Engl J Med. (2013) 369:840-51. doi: 10.1056/NEJMra1208623

50. Fay KT, Klingensmith NJ, Chen CW, Zhang W, Sun Y, Morrow KN, et al. The gut microbiome alters immunophenotype and survival from sepsis. FASEB J. (2019) 33:11258-69. doi: 10.1096/fj.201802188R

51. Inoue Y, Kohno S, Miyazaki T, Yamaguchi K. Effect of a platelet activating factor antagonist and antithrombin III on septicemia and endotoxemia in rats. Tohoku J Exp Med. (1991) 163:175-85. doi: 10.1620/tjem.163.175

52. Rayes J, Lax S, Wichaiyo S, Watson SK, Di Y, Lombard S, et al. The podoplanin-CLEC-2 axis inhibits inflammation in sepsis. Nat Commun. (2017) 8:2239. doi: 10.1038/s41467-017-02402-6

53. Vardon Bounes F, Memier V, Marcaud M, Jacquemin A, HamzehCognasse H, Garcia C, et al. Platelet activation and prothrombotic properties in a mouse model of peritoneal sepsis. Sci Rep. (2018) 8:13536. doi: $10.1038 /$ s41598-018-31910-8
54. Zarbock A, Polanowska-Grabowska RK, Ley K. Platelet-neutrophilinteractions: linking hemostasis and inflammation. Blood Rev. (2007) 21:99111. doi: 10.1016/j.blre.2006.06.001

55. Wang Z, Su F, Rogiers P, Vincent JL. Beneficial effects of recombinant human activated protein C in a ewe model of septic shock. Crit Care Med. (2007) 35:2594-600. doi: 10.1097/01.CCM.0000287590.55294.40

56. Wigton DH, Kociba GJ, Hoover EA. Infectious canine hepatitis: animal model for viral-induced disseminated intravascular coagulation. Blood. (1976) 47:287-96. doi: 10.1182/blood.V47.2.287.bloodjournal472287

57. Clar C, Oseni Z, Flowers N, Keshtkar-Jahromi M, Rees K. Influenza vaccines for preventing cardiovascular disease. Cochrane Database Syst Rev. (2015) CD005050. doi: 10.1002/14651858.CD005050.pub3. [Epub ahead of print].

58. Linder M, Muller-Berghaus G, Lasch HG, Gagel C. Virus infection and blood coagulation. Thromb Diath Haemorrh. (1970) 23:1-11.

59. Yang Y, Tang H. Aberrant coagulation causes a hyper-inflammatory response in severe influenza pneumonia. Cell Mol Immunol. (2016) 13:432-42. doi: $10.1038 / \mathrm{cmi} .2016 .1$

60. Cui S, Fu Z, Feng Y, Xie X, Ma X, Liu T, et al. The disseminated intravascular coagulation score is a novel predictor for portal vein thrombosis in cirrhotic patients with hepatitis B. Thromb Res. (2018) 161:711. doi: 10.1016/j.thromres.2017.11.010

61. Geisbert TW, Young HA, Jahrling PB, Davis KJ, Kagan E, Hensley LE. Mechanisms underlying coagulation abnormalities in ebola hemorrhagic fever: overexpression of tissue factor in primate monocytes/macrophages is a key event. J Infect Dis. (2003) 188:1618-29. doi: 10.1086/379724

62. Schechter ME, Andrade BB, He T, Richter GH, Tosh KW, Policicchio $\mathrm{BB}$, et al. Inflammatory monocytes expressing tissue factor drive SIV and HIV coagulopathy. Sci Transl Med. (2017) 9:eaam5441. doi: 10.1126/scitranslmed.aam5441

63. Short KR, Kroeze E, Fouchier RAM, Kuiken T. Pathogenesis of influenzainduced acute respiratory distress syndrome. Lancet Infect Dis. (2014) 14:5769. doi: 10.1016/S1473-3099(13)70286-X

64. Le VB, Schneider JG, Boergeling Y, Berri F, Ducatez M, Guerin JL, et al. Platelet activation and aggregation promote lung inflammation and influenza virus pathogenesis. Am J Respir Crit Care Med. (2015) 191:804-19. doi: 10.1164/rccm.201406-1031OC

65. Ashar HK, Mueller NC, Rudd JM, Snider TA, Achanta M, Prasanthi M, et al. The role of extracellular histones in influenza virus pathogenesis. Am J Pathol. (2018) 188:135-48. doi: 10.1016/j.ajpath.2017.09.014

66. Yacoub D, Hachem A, Theoret JF, Gillis MA, Mourad W, Merhi Y. Enhanced levels of soluble CD40 ligand exacerbate platelet aggregation and thrombus formation through a CD40-dependent tumor necrosis factor receptor-associated factor-2/Rac1/p38 mitogen-activated protein kinase signaling pathway. Arterioscler Thromb Vasc Biol. (2010) 30:2424-33. doi: 10.1161/ATVBAHA.110.216143

67. Kipnis E, Guery BP, Tournoys A, Leroy X, Robriquet L, Fialdes $\mathrm{P}$, et al. Massive alveolar thrombin activation in Pseudomonas aeruginosa-induced acute lung injury. Shock. (2004) 21:444-51. doi: 10.1097/00024382-200405000-00008

68. Renckens R, Roelofs JJ, Stegenga ME, Florquin S, Levi M, Carmeliet P, et al. Transgenic tissue-type plasminogen activator expression improves host defense during Klebsiella pneumonia. J Thromb Haemost. (2008) 6:660-8. doi: 10.1111/j.1538-7836.2008.02892.x

69. Skjeflo EW, Christiansen D, Fure H, Ludviksen JK, Woodruff TM, Espevik $\mathrm{T}$, et al. Staphylococcus aureus-induced complement activation promotes tissue factor-mediated coagulation. J Thromb Haemost. (2018) 16:905-18. doi: $10.1111 /$ jth.13979

70. Korhonen TK, Haiko J, Laakkonen L, Jarvinen HM, Westerlund-Wikstrom B. Fibrinolytic and coagulative activities of Yersinia pestis. Front Cell Infect Microbiol. (2013) 3:35. doi: 10.3389/fcimb.2013.00035

71. Sun H, Ringdahl U, Homeister JW, Fay WP, Engleberg NC, Yang AY, et al. Plasminogen is a critical host pathogenicity factor for group A streptococcal infection. Science. (2004) 305:1283-6. doi: 10.1126/science.1101245

72. Luo D, Szaba FM, Kummer LW, Plow EF, Mackman N, Gailani D, et al. Protective roles for fibrin, tissue factor, plasminogen activator inhibitor-1, and thrombin activatable fibrinolysis inhibitor, but not factor XI, during defense against the gram-negative bacterium Yersinia enterocolitica. $J$ Immunol. (2011) 187:1866-76. doi: 10.4049/jimmunol.1101094 
73. Popova TG, Millis B, Bailey C, Popov SG. Platelets, inflammatory cells, von Willebrand factor, syndecan-1, fibrin, fibronectin, and bacteria co-localize in the liver thrombi of Bacillus anthracis-infected mice. Microb Pathog. (2012) 52:1-9. doi: 10.1016/j.micpath.2011.08.004

74. Hitchcock JR, Cook CN, Bobat S, Ross EA, Flores-Langarica A, Lowe $\mathrm{KL}$, et al. Inflammation drives thrombosis after Salmonella infection via CLEC-2 on platelets. J Clin Invest. (2015) 125:4429-46. doi: 10.1172/JCI 79070

75. Wong $\mathrm{CH}$, Jenne CN, Petri B, Chrobok NL, Kubes P. Nucleation of platelets with blood-borne pathogens on Kupffer cells precedes other innate immunity and contributes to bacterial clearance. Nat Immunol. (2013) 14:785-92. doi: 10.1038/ni.2631

76. Robriquet L, Collet F, Tournoys A, Prangere T, Neviere R, Fourrier F, et al. Intravenous administration of activated protein $\mathrm{C}$ in Pseudomonas-induced lung injury: impact on lung fluid balance and the inflammatory response. Respir Res. (2006) 7:41. doi: 10.1186/1465-9921-7-41

77. Choi G, Hofstra JJ, Roelofs JJ, Florquin S, Bresser P, Levi M, et al. Recombinant human activated protein $\mathrm{C}$ inhibits local and systemic activation of coagulation without influencing inflammation during Pseudomonas aeruginosa pneumonia in rats. Crit Care Med. (2007) 35:1362-8. doi: 10.1097/01.CCM.0000261888.32654.6D

78. Matt U, Warszawska JM, Bauer M, Dietl W, Mesteri I, Doninger B, et al. $\mathrm{B} \beta(15-42)$ protects against acid-induced acute lung injury and secondary pseudomonas pneumonia in vivo. Am J Respir Crit Care Med. (2009) 180:1208-17. doi: 10.1164/rccm.200904-0626OC

79. Wollein Waldetoft K, Mohanty T, Karlsson C, Morgelin M, Frick IM, Malmstrom J, et al. Saliva-induced clotting captures streptococci: novel roles for coagulation and fibrinolysis in host defense and immune evasion. Infect Immun. (2016) 84:2813-23. doi: 10.1128/IAI.00307-16

80. Sun H, Wang X, Degen JL, Ginsburg D. Reduced thrombin generation increases host susceptibility to group A streptococcal infection. Blood. (2009) 113:1358-64. doi: 10.1182/blood-2008-07-170506

81. Kahn F, Hurley S, Shannon O. Platelets promote bacterial dissemination in a mouse model of streptococcal sepsis. Microbes Infect. (2013) 15:669-76. doi: 10.1016/j.micinf.2013.05.003

82. Pahlman LI, Morgelin M, Kasetty G, Olin AI, Schmidtchen A, Herwald H. Antimicrobial activity of fibrinogen and fibrinogen-derived peptides-a novel link between coagulation and innate immunity. Thromb Haemost. (2013) 109:930-9. doi: 10.1160/TH12-10-0739

83. Macrae FL, Duval C, Papareddy P, Baker SR, Yuldasheva N, Kearney $\mathrm{KJ}$, et al. A fibrin biofilm covers blood clots and protects from microbial invasion. J Clin Invest. (2018) 128:3356-68. doi: 10.1172/JCI 98734

84. Brown DE, McCoy MW, Pilonieta MC, Nix RN, Detweiler CS. Chronic murine typhoid fever is a natural model of secondary hemophagocytic lymphohistiocytosis. PLoS ONE. (2010) 5:e9441. doi: 10.1371/journal.pone.0009441

85. Hickey MJ, Kubes P. Intravascular immunity: the host-pathogen encounter in blood vessels. Nat Rev Immunol. (2009) 9:364-75. doi: 10.1038/nri2532

86. Feasey NA, Dougan G, Kingsley RA, Heyderman RS, Gordon MA. Invasive non-typhoidal salmonella disease: an emerging and neglected tropical disease in Africa. Lancet. (2012) 379:2489-99. doi: 10.1016/S0140-6736(11)6 1752-2

87. Wright AE, Knapp HH. A note on the causation and treatment of thrombosis occurring in connection with typhoid fever. Med Chir Trans. (1903) 86:1-19.

88. Huckstep RL. Typhoid Fever and other Salmonella Infections, E. \& Livingstone S. BJS Soc. (1962) 51:238. doi: 10.1002/bjs.1800510322

89. Mohanty S, Bakshi S, Gupta AK, Kapil A, Arya LS, Das BK. Venous thrombosis associated with Salmonella: report of a case and review of literature. Indian J Med Sci. (2003) 57:199-203.

90. Schifferdecker B, Merchan JA, Ahmar C, Worthington M, Griben A, Schainfeld RM, et al. Endovascular treatment of septic thrombophlebitis: a case report of a rare complication and review of the literature. Vasc Med. (2009) 14:47-50. doi: 10.1177/1358863X08096517

91. Ceyhan M, Kanra G, Benderlioglu B, Secmeer G, Hicsonmez G, Kirazli S. Transient protein $\mathrm{S}$ deficiency with deep venous thrombosis during Salmonella Typhimurium infection. Arch Dis Child. (1993) 68:138-9. doi: $10.1136 /$ adc.68.1.138
92. Salamon SA, Prag J. A case of superficial septic thrombophlebitis in a varicose vein caused by Salmonella panama. Clin Microbiol Infect. (2001) 7:34-6. doi: 10.1046/j.1469-0691.2001.00182.x

93. Carey J, Buchstein S, Shah S. Septic deep vein thrombosis due to Salmonella johannesburg. J Infect. (2001) 42:79-80. doi: 10.1053/jinf.2000.0762

94. Uribe JAZ, Coura FM, Nunes P, Silva MVP, de Carvalho AU, Moreira MVL, et al. Septicemic salmonellosis in pre weaned calves caused by Salmonella dublin. Res J Vet Pract. (2015) 3:69-75. doi: 10.14737/journal.rjvp/2015/3.3.69.75

95. Latour JG, Leger C, Renaud S, Simard P. On the mechanisms responsible for selection of hepatic veins as target for thrombosis following injection of endotoxin in hyperlipemic rats. Am J Pathol. (1974) 76:195-212.

96. Innes JR, Wilson C, Ross MA. Epizootic Salmonella enteritidis infection causing septic pulmonary phlebothrombosis in hamsters. J Infect Dis. (1956) 98:133-41. doi: 10.1093/infdis/98.2.133

97. Loomis WP, Johnson ML, Brasfield A, Blanc MP, Yi J, Miller SI, et al. Temporal and anatomical host resistance to chronic Salmonella infection is quantitatively dictated by Nramp1 and influenced by host genetic background. PLoS ONE. (2014) 9:e111763. doi: 10.1371/journal.pone.0111763

98. Vidal SM, Pinner E, Lepage P, Gauthier S, Gros P. Natural resistance to intracellular infections: Nrampl encodes a membrane phosphoglycoprotein absent in macrophages from susceptible (Nramp1 D169) mouse strains. J Immunol. (1996) 157:3559-68.

99. Monack DM, Bouley DM, Falkow S. Salmonella Typhimurium persists within macrophages in the mesenteric lymph nodes of chronically infected Nramp $1+/+$ mice and can be reactivated by IFNgamma neutralization. J Exp Med. (2004) 199:231-41. doi: 10.1084/jem.20031319

100. Hoiseth SK, Stocker BA. Aromatic-dependent Salmonella Typhimurium are non-virulent and effective as live vaccines. Nature. (1981) 291:238-9. doi: $10.1038 / 291238 \mathrm{a} 0$

101. Cunningham AF, Gaspal F, Serre K, Mohr E, Henderson IR, Scott-Tucker A, et al. Salmonella induces a switched antibody response without germinal centers that impedes the extracellular spread of infection. J Immunol. (2007) 178:6200-7. doi: 10.4049/jimmunol.178.10.6200

102. Ross EA, Coughlan RE, Flores-Langarica A, Bobat S, Marshall JL, Hussain $\mathrm{K}$, et al. CD31 is required on CD4+ T cells to promote $\mathrm{T}$ cell survival during Salmonella infection. J Immunol. (2011) 187:1553-65. doi: 10.4049/jimmunol.1000502

103. Bobat S, Darby M, Mrdjen D, Cook C, Logan E, Auret J, et al. Natural and vaccine-mediated immunity to Salmonella Typhimurium is impaired by the helminth Nippostrongylus brasiliensis. PLoS Negl Trop Dis. (2014) 8:e3341. doi: 10.1371/journal.pntd.0003341

104. Beristain-Covarrubias N, Perez-Toledo M, Flores-Langarica A, Zuidscherwoude M, Hitchcock JR, Channell WM, et al. Salmonellainduced thrombi in mice develop asynchronously in the spleen and liver and are not effective bacterial traps. Blood. (2019) 133:600-4. doi: 10.1182/blood-2018-08-867267

105. Tam JW, Kullas AL, Mena P, Bliska JB, van der Velden AW. CD11b+ Ly6Chi Ly6G- immature myeloid cells recruited in response to Salmonella enterica serovar Typhimurium infection exhibit protective and immunosuppressive properties. Infect Immun. (2014) 82:2606-14. doi: 10.1128/IAI.01590-13

106. Sheppard M, Webb C, Heath F, Mallows V, Emilianus R, Maskell $\mathrm{D}$, et al. Dynamics of bacterial growth and distribution within the liver during Salmonella infection. Cell Microbiol. (2003) 5:593-600. doi: 10.1046/j.1462-5822.2003.00296.x

107. Conlan JW, North RJ. Listeria monocytogenes, but not Salmonella Typhimurium, elicits a CD18-independent mechanism of neutrophil extravasation into the murine peritoneal cavity. Infect Immun. (1994) 62:2702-6.

108. Gonzalez-Escobedo G, La Perle KM, Gunn JS. Histopathological analysis of Salmonella chronic carriage in the mouse hepatopancreatobiliary system. PLoS ONE. (2013) 8:e84058. doi: 10.1371/journal.pone.0084058

109. Erova TE, Kirtley ML, Fitts EC, Ponnusamy D, Baze WB, Andersson JA, et al. Protective immunity elicited by oral immunization of mice with Salmonella enterica Serovar Typhimurium Braun Lipoprotein (Lpp) and Acetyltransferase (MsbB) mutants. Front Cell Infect Microbiol. (2016) 6:148. doi: $10.3389 /$ fcimb. 2016.00148 
110. Wickham ME, Brown NF, Provias J, Finlay BB, Coombes BK. Oral infection of mice with Salmonella enterica serovar Typhimurium causes meningitis and infection of the brain. BMC Infect Dis. (2007) 7:65. doi: 10.1186/1471-2334-7-65

111. Ross EA, Coughlan RE, Flores-Langarica A, Lax S, Nicholson J, Desanti GE, et al. Thymic function is maintained during Salmonella-induced atrophy and recovery. J Immunol. (2012) 189:4266-74. doi: 10.4049/jimmunol.1200070

112. Ross EA, Flores-Langarica A, Bobat S, Coughlan RE, Marshall JL, Hitchcock JR, et al. Resolving Salmonella infection reveals dynamic and persisting changes in murine bone marrow progenitor cell phenotype and function. Eur J Immunol. (2014) 44:2318-30. doi: 10.1002/eji.201344350

113. Suzuki-Inoue K, Fuller GL, Garcia A, Eble JA, Pohlmann S, Inoue $\mathrm{O}$, et al. A novel Syk-dependent mechanism of platelet activation by the C-type lectin receptor CLEC-2. Blood. (2006) 107:542-9. doi: 10.1182/blood-2005-05-1994

114. Finegold MJ. Pathogenesis of plague. A review of plague deaths in the United States during the last decade. Am J Med. (1968) 45:549-54. doi: 10.1016/0002-9343(68)90171-X

115. Lucas S. The autopsy pathology of sepsis-related death. Curr Diagnost Pathol. (2007) 13:375-88. doi: 10.1016/j.cdip.2007.06.001

116. Tan KT, Lip GY. Red vs white thrombi: treating the right clot is crucial. Arch Intern Med. (2003) 163:2534-5; author reply 2535. doi: 10.1001/archinte.163.20.2534-b

117. Saracco P, Vitale P, Scolfaro C, Pollio B, Pagliarino M, Timeus F. The coagulopathy in sepsis: significance and implications for treatment. Pediatr Rep. (2011) 3:e30. doi: 10.4081/pr.2011.e30

118. Allen KS, Sawheny E, Kinasewitz GT. Anticoagulant modulation of inflammation in severe sepsis. World J Crit Care Med. (2015) 4:105-15. doi: 10.5492/wjccm.v4.i2.105

119. Davis RP, Miller-Dorey S, Jenne CN. Platelets and coagulation in infection. Clin Transl Immunol. (2016) 5:e89. doi: 10.1038/cti.2016.39

120. Yaghi S, Eisenberger A, Willey JZ. Symptomatic intracerebral hemorrhage in acute ischemic stroke after thrombolysis with intravenous recombinant tissue plasminogen activator: a review of natural history and treatment. JAMA Neurol. (2014) 71:1181-5. doi: 10.1001/jamaneurol.2014.1210

121. Akol H, Boon E, van Haren F, van der Hoeven J. Successful treatment of fulminant pneumococcal sepsis with recombinant tissue plasminogen activator. Eur J Intern Med. (2002) 13:389. doi: 10.1016/S0953-6205(02)00095-X

122. Zenz W, Muntean W, Gallistl S, Zobel G, Grubbauer HM. Recombinant tissue plasminogen activator treatment in two infants with fulminant meningococcemia. Pediatrics. (1995) 96:144-8.

123. Zenz W, Muntean W, Zobel G, Grubbauer HM, Gallistl S. Treatment of fulminant meningococcemia with recombinant tissue plasminogen activator. Thromb Haemost. (1995) 74:802-3. doi: 10.1055/s-0038-1649821

124. Warren BL, Eid A, Singer P, Pillay SS, Carl P, Novak I, et al. Caring for the critically ill patient. High-dose antithrombin III in severe sepsis: a randomized controlled trial. JAMA. (2001) 286:1869-78. doi: 10.1001/jama.286.15.1869

125. Abraham E, Reinhart K, Opal S, Demeyer I, Doig C, Rodriguez AL, et al. Efficacy and safety of tifacogin (recombinant tissue factor pathway inhibitor) in severe sepsis: a randomized controlled trial. JAMA. (2003) 290:238-47. doi: 10.1001/jama.290.2.238

126. Saito H, Maruyama I, Shimazaki S, Yamamoto Y, Aikawa N, Ohno R, et al. Efficacy and safety of recombinant human soluble thrombomodulin (ART-123) in disseminated intravascular coagulation: results of a phase III, randomized, double-blind clinical trial. J Thromb Haemost. (2007) 5:31-41. doi: 10.1111/j.1538-7836.2006.02267.x

127. Bernard GR, Vincent JL, Laterre PF, LaRosa SP, Dhainaut JF, LopezRodriguez A, et al. Recombinant human protein, efficacy and safety of recombinant human activated protein $\mathrm{C}$ for severe sepsis. $\mathrm{N} \mathrm{Engl} \mathrm{J} \mathrm{Med.}$ (2001) 344:699-709. doi: 10.1056/NEJM200103083441001

128. Zenz W, Zoehrer B, Levin M, Fanconi S, Hatzis TD, Knight G, et al. Use of recombinant tissue plasminogen activator in children with meningococcal purpura fulminans: a retrospective study. Crit Care Med. (2004) 32:1777-80. doi: 10.1097/01.CCM.0000133667.86429.5D

129. Jaimes F, De La Rosa G, Morales C, Fortich F, Arango C, Aguirre $\mathrm{D}$, et al. Unfractioned heparin for treatment of sepsis: a randomized clinical trial (The HETRASE Study). Crit Care Med. (2009) 37:1185-96. doi: 10.1097/CCM.0b013e31819c06bc

130. Warnock LB, Huang D. Heparin. Treasure Island, FL: StatPearls (2019).

131. Fuchs TA, Bhandari AA, Wagner DD. Histones induce rapid and profound thrombocytopenia in mice. Blood. (2011) 118:3708-14. doi: 10.1182/blood-2011-01-332676

132. Ma AC, Kubes P. Platelets, neutrophils, and neutrophil extracellular traps (NETs) in sepsis. J Thromb Haemost. (2008) 6:415-20. doi: $10.1111 / \mathrm{j} .1538-7836.2007 .02865 . \mathrm{x}$

133. Jenne CN, Wong CH, Zemp FJ, McDonald B, Rahman MM, Forsyth PA, et al. Neutrophils recruited to sites of infection protect from virus challenge by releasing neutrophil extracellular traps. Cell Host Microbe. (2013) 13:169-80. doi: 10.1016/j.chom.2013.01.005

134. Claushuis TAM, de Vos AF, Nieswandt B, Boon L, Roelofs J, de Boer OJ, et al. Platelet glycoprotein VI aids in local immunity during pneumoniaderived sepsis caused by gram-negative bacteria. Blood. (2018) 131:864-76. doi: 10.1182/blood-2017-06-788067

135. Lax S, Rayes J, Wichaiyo S, Haining EJ, Lowe K, Grygielska B, et al. Platelet CLEC-2 protects against lung injury via effects of its ligand podoplanin on inflammatory alveolar macrophages in the mouse. Am J Physiol Lung Cell Mol Physiol. (2017) 313:L1016-29. doi: 10.1152/ajplung.00023.2017

136. Rayes J, Watson SP, Nieswandt B. Functional significance of the platelet immune receptors GPVI and CLEC-2. J Clin Invest. (2019) 129:12-23. doi: 10.1172/JCI122955

137. Astarita JL, Acton SE, Turley SJ. Podoplanin: emerging functions in development, the immune system, and cancer. Front Immunol. (2012) 3:283. doi: 10.3389/fimmu.2012.00283

138. Payne H, Ponomaryov T, Watson SP, Brill A. Mice with a deficiency in CLEC2 are protected against deep vein thrombosis. Blood. (2017) 129:2013-20. doi: 10.1182/blood-2016-09-742999

139. Lax S, Rayes J, Thickett DR, Watson SP. Effect of anti-podoplanin antibody administration during lipopolysaccharide-induced lung injury in mice. BMJ Open Respir Res. (2017) 4:e000257. doi: 10.1136/bmjresp-2017-000257

140. Harrison MJ, Chimen M, Hussain M, Iqbal AJ, Senis YA, Nash GB, et al. Signalling through Src family kinase isoforms is not redundant in models of thrombo-inflammatory vascular disease. J Cell Mol Med. (2018) 22:4317-27. doi: 10.1111/jcmm. 13721

141. Watson SP, Herbert JM, Pollitt AY. GPVI and CLEC-2 in hemostasis and vascular integrity. J Thromb Haemost. (2010) 8:1456-67. doi: $10.1111 /$ j.1538-7836.2010.03875.x

142. Li Z, Delaney MK, O’Brien KA, Du X. Signaling during platelet adhesion and activation. Arterioscler Thromb Vasc Biol. (2010) 30:2341-9. doi: 10.1161/ATVBAHA.110.207522

143. Li Z, Zhang G, Liu J, Stojanovic A, Ruan C, Lowell CA, et al. An important role of the SRC family kinase Lyn in stimulating platelet granule secretion. $J$ Biol Chem. (2010) 285:12559-70. doi: 10.1074/jbc.M109.098756

144. Nicolson PLR, Hughes CE, Watson S, Nock SH, Hardy AT, Watson CN, et al. Inhibition of Btk by Btk-specific concentrations of ibrutinib and acalabrutinib delays but does not block platelet aggregation to GPVI. Haematologica. (2018) 103:2097-108. doi: 10.3324/haematol.2018.193391

145. Andonegui G, Kerfoot SM, McNagny K, Ebbert KV, Patel KD, Kubes P. Platelets express functional Toll-like receptor-4. Blood. (2005) 106:2417-23. doi: 10.1182/blood-2005-03-0916

146. Clark SR, Ma AC, Tavener SA, McDonald B, Goodarzi Z, Kelly MM, et al. Platelet TLR4 activates neutrophil extracellular traps to ensnare bacteria in septic blood. Nat Med. (2007) 13:463-9. doi: 10.1038/nm1565

147. McDonald B, Urrutia R, Yipp BG, Jenne CN, Kubes P. Intravascular neutrophil extracellular traps capture bacteria from the bloodstream during sepsis. Cell Host Microbe. (2012) 12:324-33. doi: 10.1016/j.chom.2012.06.011

148. McDonald B, Davis RP, Kim SJ, Tse M, Esmon CT, Kolaczkowska E, et al. Platelets and neutrophil extracellular traps collaborate to promote intravascular coagulation during sepsis in mice. Blood. (2017) 129:1357-67. doi: 10.1182/blood-2016-09-741298

149. Martinod K, Fuchs TA, Zitomersky NL, Wong SL, Demers M, Gallant M,et al. PAD4-deficiency does not affect bacteremia in polymicrobial sepsis and ameliorates endotoxemic shock. Blood. (2015) 125:1948-56. doi: 10.1182/blood-2014-07-587709 
150. Jimenez-Alcazar M, Rangaswamy C, Panda R, Bitterling J, Simsek YJ, Long AT, et al. Host DNases prevent vascular occlusion by neutrophil extracellular traps. Science. (2017) 358:1202-6. doi: 10.1126/science.aam8897

151. Mai SH, Khan M, Dwivedi DJ, Ross CA, Zhou J, Gould TJ, et al. Delayed but not early treatment with DNase reduces organ damage and improves outcome in a murine model of sepsis. Shock. (2015) 44:166-72. doi: 10.1097/SHK.0000000000 000396

152. Brinkmann V, Reichard U, Goosmann C, Fauler B, Uhlemann Y, Weiss DS, et al. Neutrophil extracellular traps kill bacteria. Science. (2004) 303:1532-5. doi: $10.1126 /$ science. 1092385
Conflict of Interest: The authors declare that the research was conducted in the absence of any commercial or financial relationships that could be construed as a potential conflict of interest.

Copyright (c) 2019 Beristain-Covarrubias, Perez-Toledo, Thomas, Henderson, Watson and Cunningham. This is an open-access article distributed under the terms of the Creative Commons Attribution License (CC BY). The use, distribution or reproduction in other forums is permitted, provided the original author(s) and the copyright owner(s) are credited and that the original publication in this journal is cited, in accordance with accepted academic practice. No use, distribution or reproduction is permitted which does not comply with these terms. 